\title{
A Virtual Environment for Enterprise Engineering Education
}

\author{
Scott E. Grasman ${ }^{1}$, Can Saygin ${ }^{1}$, Benjamin L. Dow ${ }^{1}$, Raymond M. Kluczny ${ }^{2}$, Majdi Najm ${ }^{3}$ \\ ${ }^{1}$ Department of Engineering Management, University of Missouri - Rolla \\ ${ }^{2}$ School of Management and Information Systems, University of Missouri - Rolla \\ ${ }^{3}$ E-business University Competency Center, University of Missouri
}

\begin{abstract}
Several resources highlight the need to effectively use modern technology to gain more productive and rewarding undergraduate science, mathematics, engineering, and technology education. In addition to the growth of information technology, the importance of hands-on practice and active learning has been highlighted in various resources. These factors, coupled with inadequate and insufficient real-world experiences in undergraduate education, have become a major reason for under-qualified and under-employed graduates. This paper discusses the creation of the University of Missouri Virtual Enterprise, which provides context for development of learning modules for enterprise engineering education. This approach will improve the undergraduate education experience by developing, and introducing into the classroom, a variety of real-world enterprise engineering concepts developed in coordination with on-going research projects.
\end{abstract}

\section{Background}

In 1999, the University of Missouri E-Business Program was established to support a learning environment where students, faculty, and businesses work together toward understanding and enhancing the principles upon which today's global and complex enterprises are created and operated successfully. Innovative curricula using the latest in technology and teaching methods are continuously evolving to match the needs of industry with the knowledge and skills of students.

The business world has recognized the value of the program since its inception. Industrial partners have helped establish a solid computing and support infrastructure by providing hardware and software grants in excess of $\$ 1$ million. The program is strongly supported by the UM System central administration, and is run by a program coordinator and a coordination team, including faculty and administrative representation from each participating campus. A full-time technical staff is in place to support the computing environment and the E-Business University Competency Center web portal (http://e-business.umsystem.edu/).

The program's mission is to create a learning environment where students, faculty, and industry work together toward understanding and enhancing the principles upon which modern global and complex enterprises are created and operated successfully. The objectives of the program are three-fold: 
1. To enhance courses and curricula,

2. To provide a supportive and cooperative environment where research can flourish, and

3. To create a synergetic learning and research environment through cooperative partnerships among faculty, consultants, industry, and state/federal assistance programs.

A main vision of the program is to establish the University of Missouri Virtual Enterprise, a multi-disciplinary, distributed laboratory supporting the university's educational vision.

\section{University of Missouri Virtual Enterprise}

A virtual enterprise is a temporary consortium of independent member companies coming together to quickly exploit fast-changing world-wide manufacturing opportunities. Industrial virtual enterprises assemble themselves based on cost-effectiveness and product uniqueness without regard for organization sizes, geographic locations, computing environments, technologies deployed, or processes implemented. Virtual enterprise companies share costs, skills, and core competencies that collectively enable them to access global markets and worldclass solutions their members could not deliver individually.

The University of Missouri Virtual Enterprise (UMVE) facilitates a central virtual enterprise that emulates a real-world business environment. The scenario emulates the complexities of a modern virtual enterprise that integrates a variety of business processes, as shown in Figure 1.

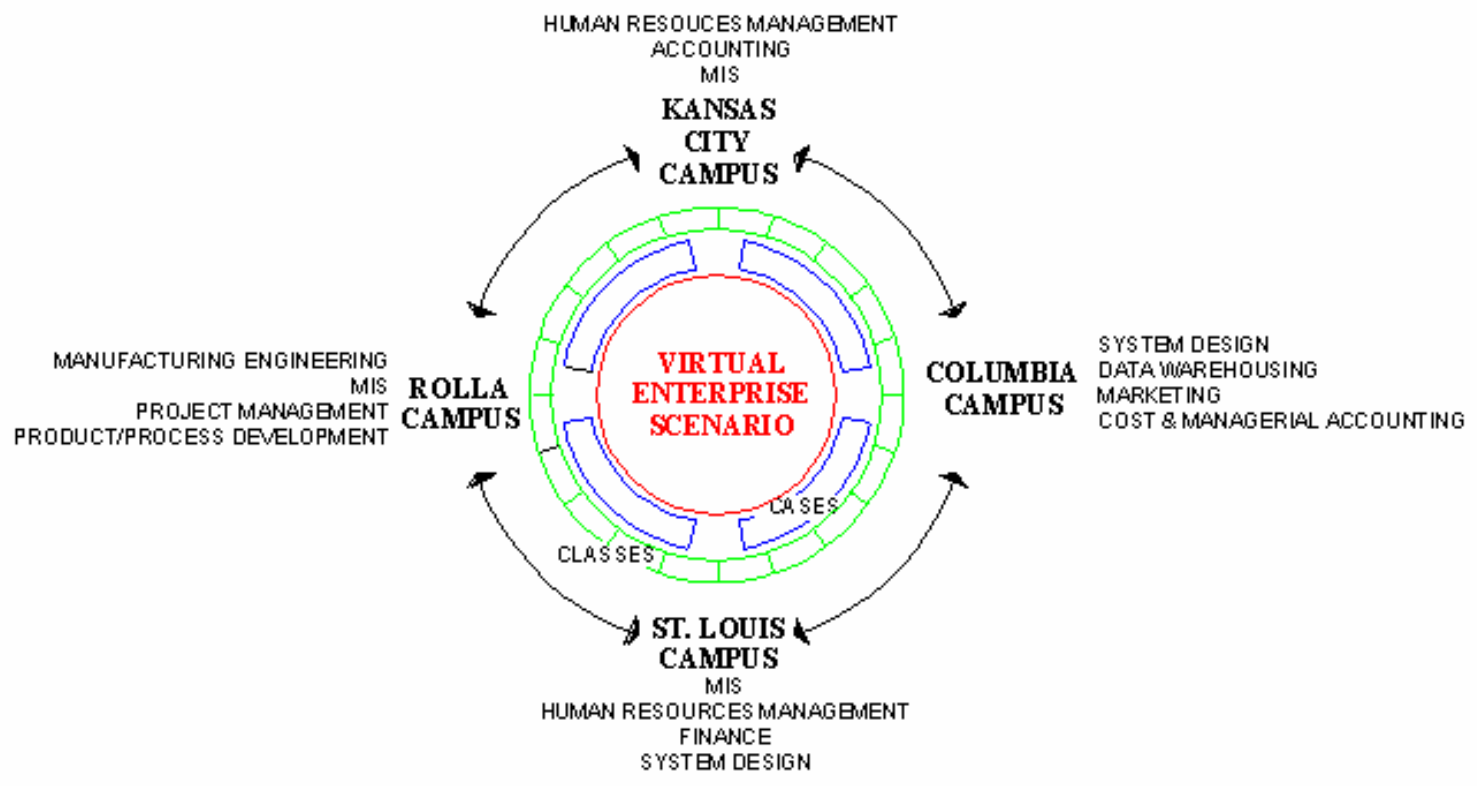

Figure 1: Components of the University of Missouri Virtual Enterprise

The UMVE creates a dynamic computer simulated environment utilizing available information technology that provides students with a hands-on and active learning experience. Academic classes, as well as businesses, play roles of various supply chain entities. Actions taken by one entity will influence the decisions made by the other entities in the virtual enterprise, thus 
accurately emulating the dynamic nature of remotely located, yet coordinated, components of a virtual enterprise.

Classes and student learning will revolve around the operation and management of the UMVE. This innovative approach to educating students allows curricula to adapt quickly to new technologies since the dynamics of the marketplace will have direct repercussions. Students will live in and operate within this continuously changing technology-based marketplace scenario. This scenario allows for the creation of:

- a teaching environment that both encourages and supports the on-going use of the student marketplace for teaching and decision-making.

- a set of role-based, pedagogical materials for use in introductory, core, and advanced classes for undergraduate, graduate, and executive education in business, information systems, and engineering.

- a data warehouse of simulated, "real-world" information over a series of years that can be used to stimulate research and the development of new ideas.

\section{Curriculum Development}

Several resources highlight the need to effectively use modern technology to gain more productive and rewarding undergraduate science, mathematics, engineering, and technology education $^{1,2}$. In addition to the growth of information technology, the importance of hands-on practice and active learning has been highlighted in various resources ${ }^{3,4}$. The creation of the UMVE provides context for development of learning modules for enterprise engineering education that will improve the education experience by developing and introducing into the classroom a variety of real-world enterprise engineering concepts, which will be developed in coordination with on-going research projects.

The framework presented by the UMVE aims to present concepts to students in an integrated computer simulated environment. In addition to the fundamental advantages of facilitating dynamic decision-making and interaction among decision makers, the data collected during dynamic interaction can be used as a series of snapshots to represent various perspectives of enterprise behavior. These snapshots can be converted into learning modules, which can be used as static, but integrated, or isolated, but dynamic learning modules for integration into current courses. The hands-on and active learning environment provides the culmination of transforming a curriculum where classes are taught in isolation into a multidisciplinary integrated environment, which will introduce students to all aspects of enterprise engineering and illustrate the need for integrative and dynamic curriculum based on real-world scenarios.

Throughout the curriculum, team-based lab and term projects will evolve from static problems that test the basic skill set to dynamic open-ended case studies and "simulated scenarios", which add depth and integrate all areas of the enterprise engineering. These scenarios will utilize the "real-world" and real-time information provided through the UMVE, and students will have the opportunity to formulate real-world problems so that they gain the ability to apply classroom models. Advanced classes will use the scenario-based cases to learn about the complexity and 
interdependence of functions within an enterprise, and results of class and research projects may be incorporated in the operations of the UMVE. Additionally, potential industry-sponsored projects will allow students to gain industrial experience and an even better understanding of the practical application of underlying theories.

\section{Example Classroom Application}

The scenario provides the background context for development of several cases, which describe a business situation arising from the UMVE. A class learns about specific business issues by analyzing the scenario and one or more cases, which address concepts and applications related to enterprise engineering including:

- accounting

- information systems,

- management,

- marketing,

- design issues,

- manufacturing and post-manufacturing issues,

- logistics relate issues, and

- other related enterprise engineering concepts.

Potential case topics include: E-commerce, Data Management, Organizational Dynamics, Governance and Legal Issues, Supply Chain Management, Business Process Re-engineering, Customer Relationship Management, and Internet Manufacturing.

The incorporation of the enterprise engineering philosophy into the curricula is illustrated by the following scenario:

A new system specified by a marketing class could be designed by engineering design students. The system would then be produced in an assembly cell operated by manufacturing engineering students. The production management students would work with process planners to develop the required operation routers. Accounting and Management students would participate in developing a business justification and planning and control mechanisms. Marketing students would be involved in developing a business and advertising/marketing plan. Information systems and accounting students would be involved in designing appropriate decision support and reporting systems to facilitate informed decision-making by the various functions. Computer science and computer engineering students would be involved at several levels by developing computer applications and interfaces to support communications, control systems, data sharing and other integration needs.

Just as in actual virtual enterprise operations, once the initial scenario environment is established, events will start unfolding over time resulting from the influence of the various partners in the enterprise, for example, a new partnership with an international company might be deemed necessary. Several questions may then emerge that could be addressed by case studies. 


\section{Distributed Learning}

The University of Missouri is heavily involved in distance-learning. This infrastructure plays a key role in the coordination of efforts among the various components of the UMVE by enabling collaboration among faculty across the campuses. Faculty members will naturally be drawn to use the established distance-learning infrastructure and deliver courses across the four campuses, resulting in the creation of geographically-dispersed student teams that will require the utilization of groupware and other internet-based tools to facilitate communication and delivery of results. In addition, the UMVE provides a learning environment for current distance-learning courses.

Proposed Extension: Simulated Marketplace for the Advancement of Research and Teaching

The Student Marketplace for the Advancement of Research and Teaching (SMART) aims to create a simulated economic environment where participating schools will be able to deliver a world-class, technology-enabled education. The SMART pilot project will provide a mechanism for the participants (students, teachers, and schools) to employ simulated business decisions. The project vision is to develop and test a role-based, technology-enabled marketplace that connects five international schools and their students in a virtual industry that encourages and facilitates "real-world" undergraduate, graduate, and executive education. The proposed system will emulate a worldwide economy from the viewpoints of all levels of management within manufacturer, supplier, and end customer environments, as shown in Figure 2.

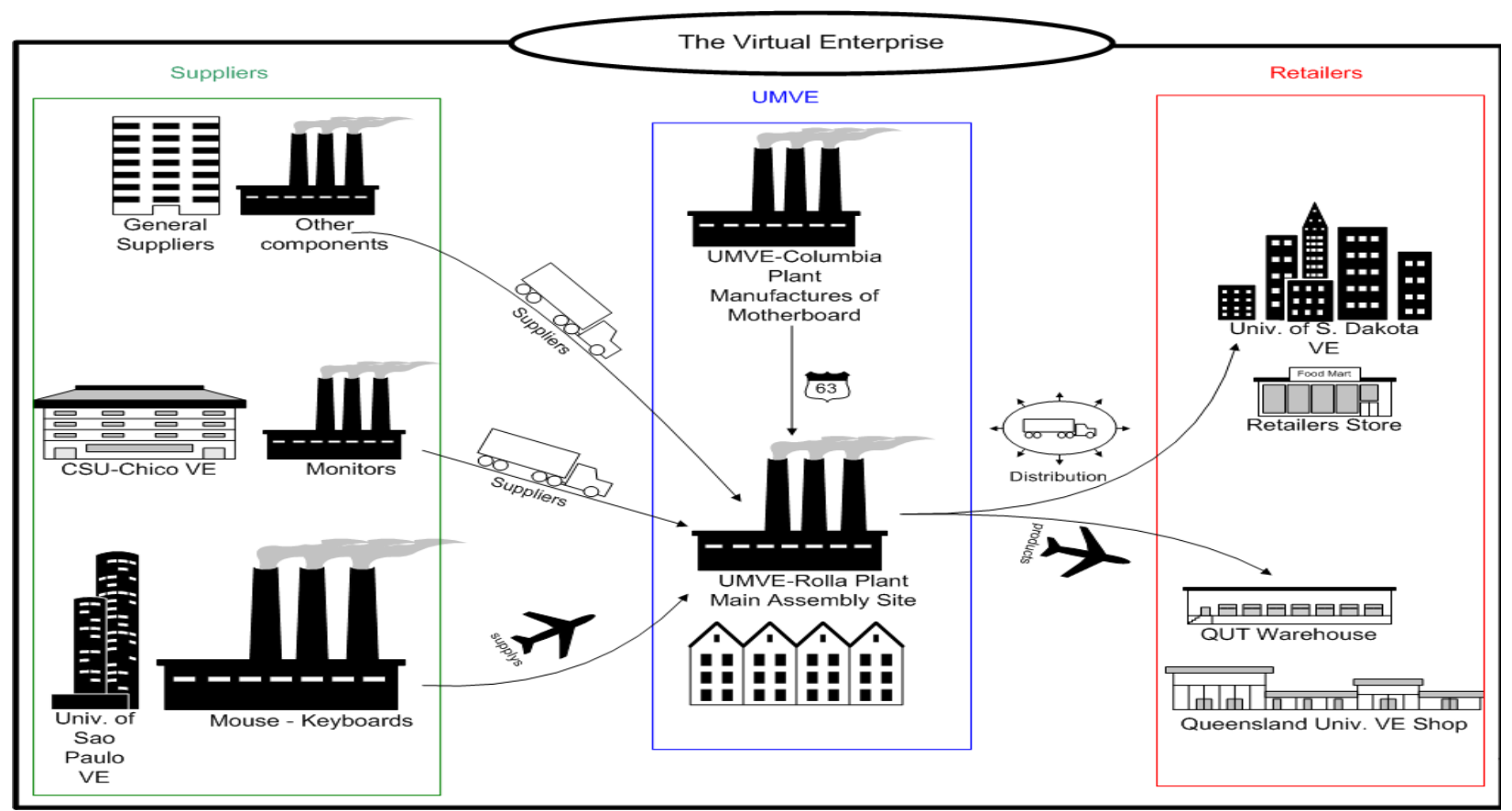

Figure 2: Structure of Simulated Marketplace 
SMART will allow students to test their decision-making skills at both the tactical and strategic management levels while concurrently providing a solid foundation for education and training across a broad spectrum of student experience levels. The pilot business environment will enable student teams to interact among the participating schools in the operation of a limited, virtual e-business simulated marketplace. It will provide a unique and challenging opportunity where students will use prior knowledge and concepts garnered in their education to make decisions that will ultimately lead to a better understanding of business and an enhanced set of skills and tools.

\section{Conclusion}

The University of Missouri Virtual Enterprise emulates the complex, real-world business environment of a modern enterprise and integrates a variety of business processes throughout its supply chain using electronic commerce, shared data and other internet-based tools. The project creates a dynamic computer simulated environment utilizing available information technology and provides context for development of hands-on and active learning modules for enterprise engineering education. The UMVE is coordinated by a faculty board, staffed by students, and receives technical support from the University of Missouri E-Business University Competency Center. This arrangement presents a live laboratory for the development of a series of interdisciplinary courses, as well as a tool for enterprise engineering research.

\section{References}

[1] Advisory Committee to the National Science Foundation, Directorate for Education and Human Resources, "Shaping the Future: New Expectations for Undergraduate Education in Science, Mathematics, Engineering, and Technology (SME\&T)", NSF 96-139.

[2] Holton, G., Professor of Physics, Harvard University, "Introductory Comments", National Research Council / NSF Symposium on Science, Mathematics, Engineering, and Technology Education, Boston, 1995.

[3] Wingspread Group on Higher Education, William E. Brock (Chair), "An American Imperative: Higher Expectations for Higher Education”, Racine, 1993.

[4] Seymour, E. and Hewitt, N., "Talking About Leaving: Factors Contributing to High Attrition Rates Among Science, Mathematics, and Engineering Undergraduate Majors", Boulder, University of Colorado, 1994.

\section{Biographical Information}

\section{SCOTT E. GRASMAN}

Scott E. Grasman is an Assistant Professor of Engineering Management at the University of Missouri - Rolla. He received his Ph.D. in Industrial and Operations Engineering from the University of Michigan. His research interests include operations and supply chain management, operations research, simulation, financial engineering and engineering economics. He is a member of ASEE, ASEM, DSI, IIE and INFORMS. 


\section{CAN SAYGIN}

Can Saygin is an Assistant Professor of Engineering Management at the University of Missouri - Rolla, and Director of the Integrated Systems Facility. He received his Ph.D. in Mechanical Engineering from the Middle East Technical University in Turkey His research interests span a wide range of manufacturing, including computer integrated manufacturing and web-based system control. He is a member of ASEE, ASEM, and SME.

\section{BENJAMIN L. DOW}

Benjamin L. Dow is a Visiting Professor of Engineering Management at the University of Missouri - Rolla. He received his Ph.D. in Nuclear Engineering from Purdue University. His research interests include energy research and development, as well as project management. He is a Registered Professional Engineer, and a member of ASEE and the American Nuclear Society.

\section{RAYMOND M. KLUCZNY}

Raymond M. Kluczny is the Associate Dean of the School of Management and Information Systems at the University of Missouri - Rolla. He received his Ph.D. in Industrial Engineering from Arizona State University. His research interests include management information and decision support systems, reliability and experimental

design. He is a member of ACM, DSI, American Accounting Association, and American Marketing Association.

\section{MAJDI NAJM}

Majdi Najm is the Director of the E-Business University Competency Center at the University of Missouri. He received his D. Eng. in Mechanical Engineering from Texas A\&M University. His current research interests include enterprise-wide integration, virtual manufacturing, instructional technology, and project management. He is a Registered Professional Engineer, certified Project Management Professional. 